\title{
British Nuclear Culture: Official and Unofficial Narratives in the Long 20th Century
}

Review Number: 2003

Publish date: Wednesday, 12 October, 2016

Author: Jonathan Hogg

ISBN: 9781441141330

Date of Publication: 2016

Price: $£ 65.00$

Pages: 248pp.

Publisher: Bloomsbury Academic

Publisher url: http://www.bloomsbury.com/uk/british-nuclear-culture-9781441141330/

Place of Publication: London

Reviewer: Richard J. E. Brown

Historians of pretty well every field and period have long acknowledged that historical enquiry cannot (indeed, must not) be limited to describing the actions and experiences of elites. In growing numbers and with growing confidence, historians have found new ways of engaging with the experiences and perceptions of past societies on a more holistic level - including through the examination of the thoughts and ideas which permeated (and often underpinned) cultures and communities of interest. In the relatively young field of nuclear history, this welcome impulse away from the apparent default mode of 'great man' narratives has taken the form of an increasing interest in 'nuclear culture'. This is a somewhat nebulous term, within which are encompassed various means of interpreting popular and unofficial engagement with the various applications of nuclear physics. Jonathan Hogg's new book, British Nuclear Culture: Official and Unofficial Narratives in the Long $20^{\text {th }}$ Century, represents a welcome effort to drive forward this still-nascent line of enquiry in the specific context of British nuclear history.

Writing a book like British Nuclear Culture is undoubtedly an ambitious undertaking. Noticeable from the outset is the author's choice of period: rather than book-ending his account with those great watersheds of 20th-century history, the atomic bombings and the end of the Cold War, Hogg begins his study with the discovery of radium in the late 19th century, and ends it almost in the present day. This broadening of focus to cover the 'long 20th century' serves Hogg's purpose in two useful ways. First, it enables him to demonstrate that the atom bomb had a prehistory, and that concepts of radioactivity and atomic energy had permeated British culture long before Hiroshima - an important observation in its own right. Second, it enables him to remind the reader that the issues arising from the practical application of nuclear physics endure, and that manifestations of the nuclear state are as relevant to contemporary British culture as to that of the 1980s and earlier.

Hogg consciously identifies four main interpretive strands to his work. These are: (1) 'British nuclear culture'; (2) 'the importance of language'; (3) 'official \& unofficial narratives'; and (4) 'nuclear anxiety'. These strands or themes are notionally threaded through the entire account, but are addressed most directly in Hogg's concise introduction. Each merits some comment. 
Hogg's first strand has to do with the very concept of British nuclear culture, which Hogg acknowledges as 'problematic' (p. 5). Drawing heavily on contributions to a 2012 special issue of the British Journal for the History of Science (in which his own work also figured prominently), Hogg acknowledges that British nuclear culture is a complex, contestable and, thanks to persistent secrecy, still partially occluded field of study. Even so, Hogg is punctilious enough a historian to present a definition of his own to underpin the work that follows:

'For the purposes of this book, I define British nuclear culture as the distinct corner of British culture characterized by the development of the nuclear state and the complex and varied ways in which people controlled, responded to, resisted or represented the complex influence of nuclear science and technology, the official nuclear state and the threat of nuclear war.' (p. 7)

This provisional definition addresses the nuclear aspect of 'British nuclear culture' in laudable depth. Yet the same cannot quite be said for the other components of the definition. What does Hogg mean by culture? Are we dealing here with culture in the civilizational, or in the social-anthropological sense? What, for that matter, does he mean by British? What are the bounds of 'Britishness' in the context of his study? The issue here is that the object of study - British nuclear culture - is identifiable only as a composite of several concepts, none of which reflects a discrete category. Bereft of a more holistic definition, the reader is, for the most part, left to infer Hogg's actual understanding of 'British nuclear culture' from his selection of sources and his mode of analysis. Perhaps this is for the best: it may well be that a composite of three contestable terms can never be more than the sum of its parts. (How much better, though, if instead of invoking 'culture' with what Clifford Geertz once called a 'studied vagueness', historians would adopt as succinct a conception of it as Geertz managed! The idea of culture as 'an historically transmitted pattern of meanings embodied in symbols ... by means of which men communicate, perpetuate, and develop their knowledge about and attitudes toward life' would seem readily applicable to the unique characteristics of the 'nuclear state'). At any rate, as rendered by Hogg, the emphasis is on nuclear-influenced forms of control, response, resistance and representation, and what this amounts to in practice is a focus on popular culture, journalism, and hardest of all to pin down - 'everyday life'.

Hogg's other interpretative strands have rather more concrete foundations. His second strand has to do with the importance of language, and the ways in which words become freighted with meaning, feeding into - or perhaps ultimately disrupting - structures of power. The analyses that follow testify to Hogg's appreciation of this point: he is undoubtedly alive to the nuances of nuclear terminology and the different uses to which terms from the nuclear lexicon can be put. It is Hogg's third and fourth strands, though, that really reflect the bulk of Hogg's analysis. The notion of official and unofficial narratives, and the complexities of their interrelation, forms the book's main organizing concept, whilst an acute sensitivity to the phenomenon of nuclear anxiety as a pervasive influence on unofficial narratives in particular informs much of Hogg's argument.

Although Hogg usefully situates his work, recognizing his indebtedness to contemporary colleagues (such as Christoph Laucht, Jeff Hughes, and Daniel Cordle), and less directly to those of an earlier, mostly American, generation (chiefly Paul Boyer and Spencer Weart), the book is actually rather light on methodology. It is never entirely clear where Hogg's theoretical inspiration lies. Foucault is invoked early (p. 3), but his influence on Hogg's approach is never really explained, and if his ideas have had any bearing on the task at hand, they nevertheless fail to appear in the text. In the same way, there is a reference on the very first page to the atomic bomb and the Nazi Holocaust as 'signifiers' (specifically, 'of the gruesome extremes of modernity, political thought and human agency') but this does not serve as an entrée into a discussion of nuclear semiotics per se: Saussure, Peirce and friends are nowhere to be seen, and nothing as technical as a signifier is encountered in the subsequent text. This is not necessarily a bad thing: unencumbered by interdisciplinary theoretical borrowings, which so often can serve to confuse or mislead (particularly undergraduate) readers, Hogg has allowed himself space to create something truly accessible. In that sense, 
the introduction's relative lack of historiographical red meat might serve as a strength, rather than a weakness.

At any rate, what follows the introductory chapter is an impressively cohesive dash through 12 decades of nuclear history. In the space of six broadly self-contained chapters, Hogg moves from the period prior to the public's first encounter with the bomb (1898-1945) to the public's 'early' and 'maturing' responses to the arrival of the nuclear age (1945-1950 and 1950-1958, respectively), and from there to the development of increasingly extreme unofficial narratives (1959-1975), the increasing prominence of those extreme narratives in critical political discourse and artistic expression (1975-89), and on to the persistence and reformulation of nuclear culture into the present (1990-2015).

The argument - a series of arguments, really; each chapter has a distinct thesis and a brief conclusion emerges from a blizzard of references. Hogg calls on films, advertisements, local newspapers, diaries, cartoons, plays, novels, music: no obvious manifestation of 'culture' is ignored (though some have likely slipped through Hogg's net; there are limits to how much culture an individual, even a historian, can consume). Each source is taken as a reflection of some individual or group's engagement (conscious or unconscious) with nuclear culture. In stitching together these individual vignettes of British culture, Hogg is able to evoke wider transitions in British society paralleling and responding to the development of the British nuclear state; above all, he is able to show the development of unofficial/counter-narratives to the progressive development (one might equally write 'encroachment') of the 'official' nuclear state.

Since the source material is potentially as vast as British culture itself, Hogg's task naturally becomes one of selection. Which aspects of popular culture to reference? Which books, which plays, which throwaway lines, best encapsulate the lived experience, the thought world, of past generations? This could undoubtedly have been a far longer book, had Hogg not been so ruthless in selecting and presenting his material. He has certainly done well to limit himself to 175 pages of text. The challenge in doing so, of course, is somehow to steer the analysis between the Scylla of superficiality and the Charybdis of nimiety. Readers with an existing grasp on British nuclear history will certainly have formed their own concepts of what constitute the major landmarks in the development of British nuclear culture, and might therefore feel slightly short-changed to discover a treasured source dealt with only briefly. There are, for instance, only a couple of sentences on contemporary views of CP Snow's The New Men; a sentence or two on Shute's On the Beach in novel and film form; a line and a half on Briggs' When the Wind Blows, and so on. Yet the treatment of these sources is brisk rather than superficial, and good use is made of the space that this briskness opens up, for Hogg is able to pay attention instead to less well-known sources, casting welcome analytical light on them. This is the particular strength: the density of reference and the deftness of insight accompanying some of Hogg's arguments open up refreshingly novel lines of thought. By way of an example: if asked to name a film embodying early Cold War anxieties, one might well think of the Quatermass Xperiment (1955), with its atmosphere of creeping dread and core concept of scientific endeavour having unwittingly brought great peril upon a wholly defenceless world; but would These Are The Damned, a later (1963) film from the same studio, leap as readily to mind? Yet the discussion of this film's significance - and an almost throwaway juxtaposition with On the Beach - presents a serendipitous set of insights and ideas as to how the British public interpreted nuclear issues as they intersected with their own lives. Similarly stimulating vignettes are plentiful, especially in the middle chapters. There is plenty here to inspire readers, and fascinating future work may well find its germ in some flash of insight arising from these pages.

Equally inherent in the task of selection is the necessity of omission. The assortment of sources Hogg presents can only ever be subjective, and any reader who is downhearted at the thought of favourite sources receiving short shrift will be even less pleased by the prospect of their total omission. A fair-minded reader, though, will be left with the impression that the book could very nearly be rewritten using entirely different sources without necessarily altering the core argument one iota. Those same readers might rather enjoy identifying sources not mentioned by Hogg, and weighing them in light of the arguments made in British Nuclear Culture. Hogg's text makes no mention, for example, of The Mouse that Roared, a 1959 comedy which, like Dr Strangelove after it, starred Peter Sellers in multiple roles, and which had at its heart the 
newly-invented, utterly devastating 'Q Bomb'; yet the film's satirizing of deterrence theory and its core conceit of immeasurable power falling into the hands of those ill-prepared for the responsibility could be reconciled - rather interestingly - with the wider thrust of Hogg's arguments.

In such an undertaking as this, which prioritizes breadth of coverage over depth of analysis, trivial errors of fact may well be inevitable, and to seek them out for exposure to public scrutiny would be rather petty. That said, it is perhaps a little slack to assert wholly uncritically that the MAUD committee owed its name to an acronym for 'Military Application of Uranium Detonation' (p. 20). That nothing more egregious was apparent may well be testament to Hogg's thoroughness, and to the breadth of his knowledge of UK nuclear history. More interesting from a historian's point of view is the possibility of misinterpretation of sources. Hogg's approach strays perilously close to being that of a Jack-of-all-trades, never quite mastering individual sources to the extent that more closely focused historians might manage. It is certainly true that the deeper into the detail readers are willing to drill, the more likely it is that they will discover statements with which to quibble. For example, Hogg cites two items by C. S. Lewis - a poem and an essay - as implying a change in emphasis between Lewis' immediate and subsequent feelings around the dawning of the atomic age. Hogg stresses the darkness of the imagery in Lewis' 1945 poem On the Atomic BombMetrical Experiment in order to highlight the wider public's sense of 'a fearful new reality' having been unveiled to the world (p. 72). This is then contrasted with Lewis' 1948 essay 'On Living in an Atomic Age', where a more stoical attitude is apparent: rather than living in fear, one ought simply to live one's life as though nothing had changed. Yet closer analysis of both sources reveals rather more common ground than Hogg seems to allow for: Lewis' 'metrical experiment' reaction to the atomic bomb, although replete with dark imagery ('an engine/Of injury that angels/Might dread', and so on) ultimately reflects the same basic stoicism - or rather, Christian fortitude - of his later essay. 'What's here to dread?', the poem asks; 'This marks no huge advance in/The dance of Death'. This is in fact the same sentiment evident in Lewis' later prose piece, in which he cautions us not to 'begin by exaggerating the novelty of the situation'. It is important not to overstate the significance here: this slight mishandling of a single poem is no grave sin on Hogg's part. A minor distortion of Lewis' thought has very little impact on the wider argument. The point is more that Hogg's analysis here is impressionistic rather than hyper-accurate. Ultimately, what Hogg has created in British Nuclear Culture is a mosaic, composed of individual sources arranged to form a far larger picture. The same could equally be said of all historians' work, which ultimately rests on the arrangement of discrete sources to describe a wider phenomenon, but in Hogg's case the process is plainer than most; the brush strokes, as it were, are more obvious.

Hogg closes his final chapter by expressing his hope that his efforts will encourage others to engage further with the history (and future) of British nuclear culture. The sheer breadth of British Nuclear Culture and the stimulating density of its insights mean that he can have every expectation that it will achieve exactly that goal. The book would certainly work well in a classroom context, given the self-contained chapters and reader-friendly design (for example, a full-page boxout on the 1956 Hammer Film $X$ the Unknown perfectly evokes the developing sense of nuclear anxiety apparent in unofficial popular-culture narratives of the 1950s; similar boxouts highlight particularly pertinent quotations). The inclusion within the bibliography of a list of 'recommended online resources for nuclear history' is particularly welcome; the slightly perfunctory two-page chronology has less utility. The (admittedly monochrome) illustrations throughout the book are a crucial inclusion: so much of British nuclear culture is visual that to attempt to engage with the topic without reference to visual material would have been foolhardy in the extreme.

Beyond the classroom, too, there is every reason to anticipate a positive reception amongst nuclear scholars, for the reasons identified in the preceding paragraphs. Hogg has managed, sometimes consciously, sometimes inadvertently, to suggest literally dozens of potential avenues for future enquiry. A survey history of the type that Hogg has produced here is effectively fractal, in that historians can focus in on ever-more precise topics and themes within it: ideas meriting a paragraph, even a sentence, in this book might well be broadened out into substantive research elsewhere. Some such treatments may refute Hogg's broad-stroke conclusions; others may support them; all will help refine historians' understanding of the history of British nuclear culture. In the final analysis, then, the several merits of British Nuclear Culture outweigh its few 
imperfections. It will not be the last word on the history of British nuclear culture - that was never really Hogg's intention - but rather deserves credit as the first major contribution to what promises to be a significant sub-field of British nuclear history.

Source URL:https://reviews.history.ac.uk/review/2003

\section{Links}

[1] https://reviews.history.ac.uk/item/183764 